\title{
Educação Superior, deficiência e trabalho nas pesquisas de pós-graduação no período de 2008 a 2019
}

Higher Education, disability and work in postgraduate research in the period from 2008 to 2019

Educación superior, discapacidad y trabajo en investigación de posgrado en el período de 2008 a 2019

\author{
Valéria Becher Trentin \\ Professora doutora da Fundação Catarinense de Educação Especial, São José, SC, Brasil \\ E-mail: valeriatret@yahoo.com.br ORCID: https://orcid.org/0000-0003-2223-7845 \\ Tânia Regina Raitz \\ Professora pós-doutora da Universidade do Vale do Itajaí, Itajaí, SC, Brasil \\ E-mail: raitztania@gmail.com ORCID: https://orcid.org/0000-0002-4698-6077
}

Recebido em 13 de maio de 2021

Aprovado em 12 de agosto de 2021

Publicado em 31 de agosto de 2021

\section{RESUMO}

Com a Promulgação da Política de Educação Especial na Perspectiva da Educação Inclusiva (2008), a qual destaca o estreitamento entre a Educação Superior e a Educação Especial, evidencia-se o movimento de inclusão que se expandiu não só na educação básica nos últimos anos, mas também alcançando a educação superior, sendo subsidiada por normativas legais. Isto fez com que se tornasse expressivo o número de pessoas com deficiência que reivindicam o direito de ingressar e de permanecer nas universidades. $O$ ingresso na educação superior e a participação da pessoa com deficiência no mundo do trabalho, constituem um campo de complexidades e desafios que compreendem a relação existente entre educação e trabalho. $O$ presente artigo tem por objetivo averiguar as dissertações e teses realizadas no Brasil, após a promulgação da Política de Educação Especial na Perspectiva da Educação Inclusiva (2008), relacionando a escolarização da pessoa com deficiência na Educação Superior ao trabalho. Para o levantamento de dados, foi efetuada pesquisa nas bases da Coordenação de Aperfeiçoamento de Pessoal de Nível Superior (CAPES) e do Banco Digital de Teses e Dissertações (BDTD). Nas buscas realizadas, foram utilizados os seguintes descritores: educação superior; deficiência; inclusão e trabalho. As pesquisas encontradas apontam a predominância de relatos acerca da fragilidade da educação superior em ofertar conteúdos acadêmicos efetivamente associados ao mercado de trabalho. Verificou-se ainda, que a temática é nova e apresenta literatura escassa, tornando-a, além de relevante nacionalmente, também importante para universidades, professores, pesquisadores da área, agentes de políticas públicas e a sociedade como um todo.

Palavras-chave: Educação Superior; Trabalho; Pessoa com deficiência. 
http://dx.doi.org/10.5902/1984686X65766

\section{ABSTRACT}

With the Enactment of the Special Education Policy in the Inclusive Education Perspective (2008), which highlights the narrowing between Education and Special Education, the inclusion movement that has expanded in basic education in recent years, is also evident reaching also the Higher Education, subsidized by legal regulations, thus increasing the number of people with disabilities who claim the right to enter and stay in universities. Entry into higher education and the participation of people with disabilities in the world of work, is a field of complexities and challenges that comprise the relationship between education and work. This article aims to investigate the dissertations and theses carried out in Brazil, after the promulgation of the Special Education Policy from the perspective of Inclusive Education (2008), which relate the schooling of people with disabilities in Higher Education to work. To collect the data, research was carried out on the bases of the Coordination for the Improvement of Higher Education Personnel (CAPES) and the Digital Bank of Theses and Dissertations (BDTD). In the searches carried out, the following descriptors were used: higher education; deficiency; inclusion and work. The research found points in its results to the predominance of reports about the fragility of higher education in offering academic content effectively related to the labor market. It was also evident that the theme is new and presents scarce literature, making it not only nationally relevant, but also important for universities, professors, researchers in the area, public policy agents and society as a whole.

Keywords: Higher Education; Work; Disabled person.

\section{RESUMEN}

Com la Promulgación de la Política de Educación Especial en la Perspectiva de la Educación Inclusiva (2008), que destaca el estrechamiento entre Educación y Educación Especial, también se evidencia el movimiento de inclusión que se ha expandido en la educación básica en los últimos años, llegando también a la Educación Superior, subsidiado por la normativa legal, aumentando asíel número de personas con discapacidad que reclaman el derecho a ingresar y permanecer em las universidades. El ingreso a la educación superior y la participación de las personas con discapacidad en el mundo laboral, es un campo de complejidades y desafíos que comprenden la relación entre educación y trabajo. Este artículo tiene como objetivo investigar las disertaciones y tesis realizadas en Brasil, luego de la promulgación de la Política de Educación Especial desde la perspectiva de la Educación Integrada (2008), que relacionan la escolarización de las personas condiscapacidad en la Educación Superior con el trabajo. Para la recolección de los datos se realizó una investigación sobre las bases de la Coordinación de Perfeccionamiento del Personal de Educación Superior (CAPES) y el Banco Digital de Tesis y Disertaciones (BDTD). En las busque das realizadas se utilizar on los siguientes descriptores: educación superior; deficiencia; inclusión y trabajo. La investigación en contróapuntaen sus resultados al predominio de reportajes sobre la fragilidad de la educación superior en la oferta de contenidos académicos efectivamente relacionados con el mercado laboral. También se evidenció que el tema es nuevo y presenta escasa literatura, lo que lo hace no solo 
relevante a nivel nacional, sino también importante para universidades, profesores, investigadores del área, agentes de políticas públicas y lasociedad en su conjunto.

Palabras clave: Educación Superior; Trabajo; Persona discapacitada.

\section{Introdução}

Sob a influência dos consensos assinados nas conferências internacionais, o Brasil, a partir da década de 1990, instituiu uma ampla reforma na Educação. Nessa reforma, os princípios dos acordos internacionais foram incorporados à Lei de Diretrizes e Bases da Educação Nacional (LDBEN), № 9.394/96, e às resoluções, aos pareceres e aos decretos que decorreram da referida Lei. Nesse contexto, a Educação Especial foi contemplada como uma possibilidade de democratização do ensino. Prevista na Constituição Federal de 1988, a Educação Especial foi regulamentada pela LDBEN, sendo definida como modalidade de ensino a ser ofertada, preferencialmente, na rede regular de ensino aos alunos com deficiência (BRASIL, 1996). Diante das reformas educacionais impulsionadas em âmbito internacional, cabe destacar que, no Brasil, as iniciativas voltadas para a pessoa com deficiência foram intensificadas a partir dos compromissos assumidos na Convenção sobre os Direitos da Pessoa com Deficiência (BRASIL, 2007), a qual estabeleceu que os Estados-Partes devem

[...] assegurar um sistema de educação inclusiva em todos os níveis de ensino, em ambientes que maximizem o desenvolvimento acadêmico e social compatível com a meta da plena participação e inclusão, adotando medidas para garantir que: a) As pessoas com deficiência não sejam excluídas do sistema educacional geral sob alegação de deficiência e que as crianças com deficiência não sejam excluídas do ensino fundamental gratuito e compulsório, sob alegação de deficiência; b) As pessoas com deficiência possam ter acesso ao ensino fundamental inclusivo, de qualidade e gratuito, em igualdade de condições com as demais pessoas na comunidade em que vivem (BRASIL, 2007, p. 5-6).

Após a Convenção, foram feitos, no Brasil, investimentos em programas e projetos educacionais e sociais direcionados para o público-alvo da Educação Especial. Decorrente disso, em 2009, o Brasil promulgou a Convenção pelo Decreto $N^{\circ}$ 6.949/2009, considerando-se que os atos internacionais em apreço entrariam em vigor no país, no plano jurídico, em agosto de 2008.

Anteriormente ao Decreto, o governo brasileiro nomeou uma comissão de profissionais da área da Educação Especial para elaborar o texto da Política Nacional de Educação Especial na Perspectiva da Educação Inclusiva (BRASIL, 2008). A comissão 
http://dx.doi.org/10.5902/1984686X65766

realizou várias discussões e, em 2008, entregou o texto, segundo o qual a Política Nacional de Educação Especial na Perspectiva da Educação Inclusiva

\begin{abstract}
objetiva o acesso, a participação e a aprendizagem dos alunos com deficiência, transtornos globais do desenvolvimento e altas habilidades/superdotação nas escolas regulares, orientando os sistemas de ensino para promover respostas às necessidades educacionais especiais, garantindo: transversalidade da educação especial desde a educação infantil até a educação superior; [...] (BRASIL, 2008, p.8)
\end{abstract}

No tocante às resoluções, aos pareceres, aos decretos e às políticas nacionais que têm como foco a inclusão escolar, vale frisar que pressupõem o estreitamento entre a Educação Especial e a educação comum para atender à diversidade presente nas salas de aula da Educação Infantil, do Ensino Fundamental, da Educação de Jovens e Adultos e da Educação Superior, decorrente do acesso de pessoas com deficiência, síndromes, transtornos globais do desenvolvimento e altas habilidades.

Em se tratando do estreitamento entre a Educação Especial e a Educação Superior, é importante salientar que o movimento de inclusão que se expandiu na educação básica nos últimos anos alcança, também, a educação superior, subsidiada por normativas legais que tratam da garantia de direitos, tais como o Aviso Circular no 277/1996, o Decreto no 3.298/1999, a Portaria no3.284/2003 (2003) e, recentemente, a Lei no 13.146/2015 (2015), Lei Brasileira de Inclusão da Pessoa com Deficiência. Isso tornou expressivo o número de pessoas com deficiência que reivindicam o direito de ingressar e de permanecer nas universidades, o que tem provocado mudanças conceituais e atitudinais dos professores, bem como nas condições de acessibilidade na educação superior.

Sobre a inclusão de pessoas com deficiência, os dados do resumo técnico do Censo da Educação Superior, divulgados pelo Instituto de Estudo e Pesquisas Educacionais Anísio Teixeira (INEP), indicaram que 7.305.977 estudantes brasileiros efetuaram matrículas em Instituições de Ensino Superior, em 2013. Dessa amostra total, 29.034 declararam apresentar alguma necessidade especial constitutiva do público-alvo da educação especial, ou seja, alunos com deficiência, transtornos globais de desenvolvimento e altas habilidades/superdotação (BRASIL,2016).

Pode-se ressaltar, ainda, que o aumento de matrículas do público-alvo da educação especial na Educação Superior pode ser explicado pela implementação de programas governamentais de educação inclusiva voltados especificamente à educação superior. Entre eles, podem ser citados o Plano de Reestruturação e Expansão das Universidades Federais - REUNI, o Programa Universidade para Todos - PROUNI e, notadamente, o 
http://dx.doi.org/10.5902/1984686X65766

Programa de Inclusão no Ensino Superior - INCLUIR, que tem por finalidade assegurar o direito da pessoa com deficiência à educação superior, fomentando a criação e a consolidação de núcleos de acessibilidade nos Institutos Federais de Ensino Superior. Cumprindo o disposto nos Decretos ํㅜ 5.296/2004 e no 5.626/2005, o programa INCLUIR 04/2008 pretende viabilizar ações institucionais nas universidades para integrar as pessoas com deficiência à vida acadêmica e eliminar as barreiras pedagógicas, comportamentais, arquitetônicas e de comunicação que possam existir.

No entanto, torna-se pertinente enfatizar que o direito à educação não se reduz apenas às ações supracitadas, mas também ao direito de aprender. Aprender, para que a pessoa com deficiência tome consciência de seu estado de opressão a fim de que, assim, possa se libertar daqueles que a oprimem (FREIRE, 1981), ou seja, para que se obtenha o empoderamento. Desse modo, destaca-se que o ingresso na educação superior é um elemento na vida das pessoas com deficiência que proporciona a autonomia, uma vez que, para elas, a chegada nessa etapa de ensino significa que precisaram superar diversas barreiras sociais. Isto, por si só, já imprime uma postura de empoderamento, reforçada pela formação superior em si, que permite às pessoas gerir sua vida por meio da aquisição de competências que Ihes possibilitem o desenvolvimento das funções escolhidas.

Sobre as questões que envolvem o acesso ao mercado de trabalho, cabe mencionar que a pessoa com deficiência, bem como qualquer sujeito, almeja um lugar na sociedade, deseja obter bens de consumo e também trabalhar. Esses desejos são inerentes ao ser humano, independente de possuir ou não uma deficiência. É na busca pela realização dos sonhos e desejos que surge a escolarização.

No que diz respeito a este aspecto, Branco (2005) destaca os vínculos existentes entre a educação e o trabalho. $\mathrm{O}$ autor afirma "que três entre cada quatro jovens estão atribuindo ao binômio educação e trabalho o significado de assunto que mais the interessa". (BRANCO, 2005, p.140). É nesse binômio que os jovens e adultos depositam suas expectativas sempre relacionadas a um futuro imediato, mesmo que, muitas vezes, tais expectativas não sejam animadoras, sem negar que é mais difícil para os jovens e adultos com deficiência.

Todavia, mediante esse binômio, há de se considerar os resultados de pesquisas que trazem à tona as dificuldades que os jovens e adultos enfrentam na busca por oportunidades de trabalho no cenário social contemporâneo. Pais (2005), ao comentar sobre a condição de vida de pessoas menos favorecidas, seja em função da situação 
http://dx.doi.org/10.5902/1984686X65766

econômica, seja pela deficiência, caracteriza o mercado de trabalho como restrito, exigente $\mathrm{e}$, por isso, excludente. No que se refere à pessoa com deficiência, considera-se que a educação exerce um papel fundamental em sua inserção e permanência no mercado de trabalho.

Em síntese, pode-se asseverar que o principal argumento da importância do trabalho para a pessoa com deficiência, é porque ele é entendido como atividade fundamental para a manutenção da vida adulta e das relações sociais, visto que repercute e compõe a identidade e a autonomia das pessoas, além de favorecer a autoestima e a interação social de pessoas tão marcadas pela invisibilidade.

Embora o tema que envolve a relação da escolarização da pessoa com deficiência na Educação Superior e o trabalho seja pertinente, sua literatura é escassa, tornando-se urgentes debates acerca da questão, já que, seguindo o movimento inclusivo, a Educação Superior se apresenta como uma possibilidade de inclusão social.

A escassez na literatura pode ser comprovada por levantamento feito nas bases da Coordenação de Aperfeiçoamento de Pessoal de Nível Superior (CAPES) e do Banco Digital de Teses e Dissertações (BDTD), no período de 2008 a2019. Nesse sentido, é preciso questionar: como vêm se configurando as pesquisas que relacionam a escolarização das pessoas com deficiência na Educação Superior ao trabalho? Procurase, no decorrer do artigo, responder ao questionamento, à luz das pesquisas (Teses e Dissertações) de Pós-Graduação no Brasil.

Este artigo tem por objetivo averiguar as pesquisas realizadas no Brasil, após a promulgação da Política de Educação Especial na perspectiva da Educação Inclusiva (2008), relacionando a escolarização da pessoa com deficiência na Educação Superior ao trabalho. Para tanto, encontra-se dividido em três seções principais. Na primeira seção, apresentam-se a metodologia empregada na busca pelas fontes e os dados referentes ao número de pesquisas desenvolvidas em Programas de Pós-Graduação. Na segunda seção, serão abordados e discutidos os resultados das investigações efetuadas pelas pesquisas examinadas e, na terceira, as considerações finais.

\section{Metodologia e resultados}

De abordagem qualitativa, valeu-se da pesquisa bibliográfica, que, de acordo com Gil (2008), é uma técnica utilizada com grande frequência em estudos exploratórios ou descritivos, casos em que o objeto de estudo proposto é pouco estudado e implica um 
http://dx.doi.org/10.5902/1984686X65766

conjunto ordenado de procedimentos de busca de soluções, atento ao objeto de estudo. Para o desenvolvimento deste estudo, foram utilizadas como fontes de coleta de dados a Biblioteca Digital de Teses e Dissertações (BDTD) e a Coordenação de Aperfeiçoamento de Pessoal de Nível Superior (CAPES). Foram realizadas buscas por teses e dissertações a partir dos seguintes descritores: educação superior; deficiência; educação; inclusão e trabalho.

Após levantamento, foram encontradas 130 pesquisas entre teses e dissertações sobre a temática Educação Superior e Deficiência, sendo que somente 08 eram relacionadas à escolarização da pessoa com deficiência na Educação Superior e trabalho. As pesquisas foram inicialmente categorizadas por temporalidade, e percebe-se maior concentração entre os anos 2013 e 2019. Entende-se que essa concentração ocorre devido à promulgação, em 2008, da Política de Educação Especial na Perspectiva da Educação Inclusiva e da Lei Brasileira de Inclusão da Pessoa com Deficiência (Lei no 13.146/2015). Os dados são informados segundo tabela 1.

Tabela 1 - Pesquisas que relacionam a escolarização da pessoa com deficiência no Ensino Superior ao trabalho (2008/2019)

\begin{tabular}{lccc}
\hline Ano & Dissertações & Teses & Total \\
\hline 2008 & 1 & - & 1 \\
\hline 2009 & - & - & - \\
\hline 2010 & - & - & - \\
\hline 2011 & - & - & - \\
\hline 2012 & - & - & - \\
\hline 2013 & - & 1 & 1 \\
\hline 2014 & - & - & - \\
\hline 2015 & 2 & 1 & 3 \\
\hline 2016 & - & - & - \\
\hline 2017 & 1 & - & 1 \\
\hline 2018 & - & - & - \\
\hline 2019 & 1 & 1 & 2 \\
\hline Total & 5 & 3 & 8 \\
\hline
\end{tabular}

Fonte: Biblioteca Digital de Teses e Dissertações (http://bdtd.ibict.br/); Coordenação de Aperfeiçoamento de Pessoal de Nível Superior (CAPES) (http://www.capes.gov.br/). 
http://dx.doi.org/10.5902/1984686X65766

Das oito pesquisas, 3 foram desenvolvidas em instituições localizadas no estado de São Paulo, uma no Rio de Janeiro, uma em Mato Grosso do Sul, uma no Rio Grande do Norte, uma em Santa Catarina e uma no Paraná, o que nos permitiu conhecer como a relação entre Educação Superior, deficiência e trabalho vem sendo pouco debatida em pesquisas no Brasil.

Imagem 1 - Localização das Universidades com pesquisas que relacionam a escolarização da pessoa com deficiência no Ensino Superior ao trabalho

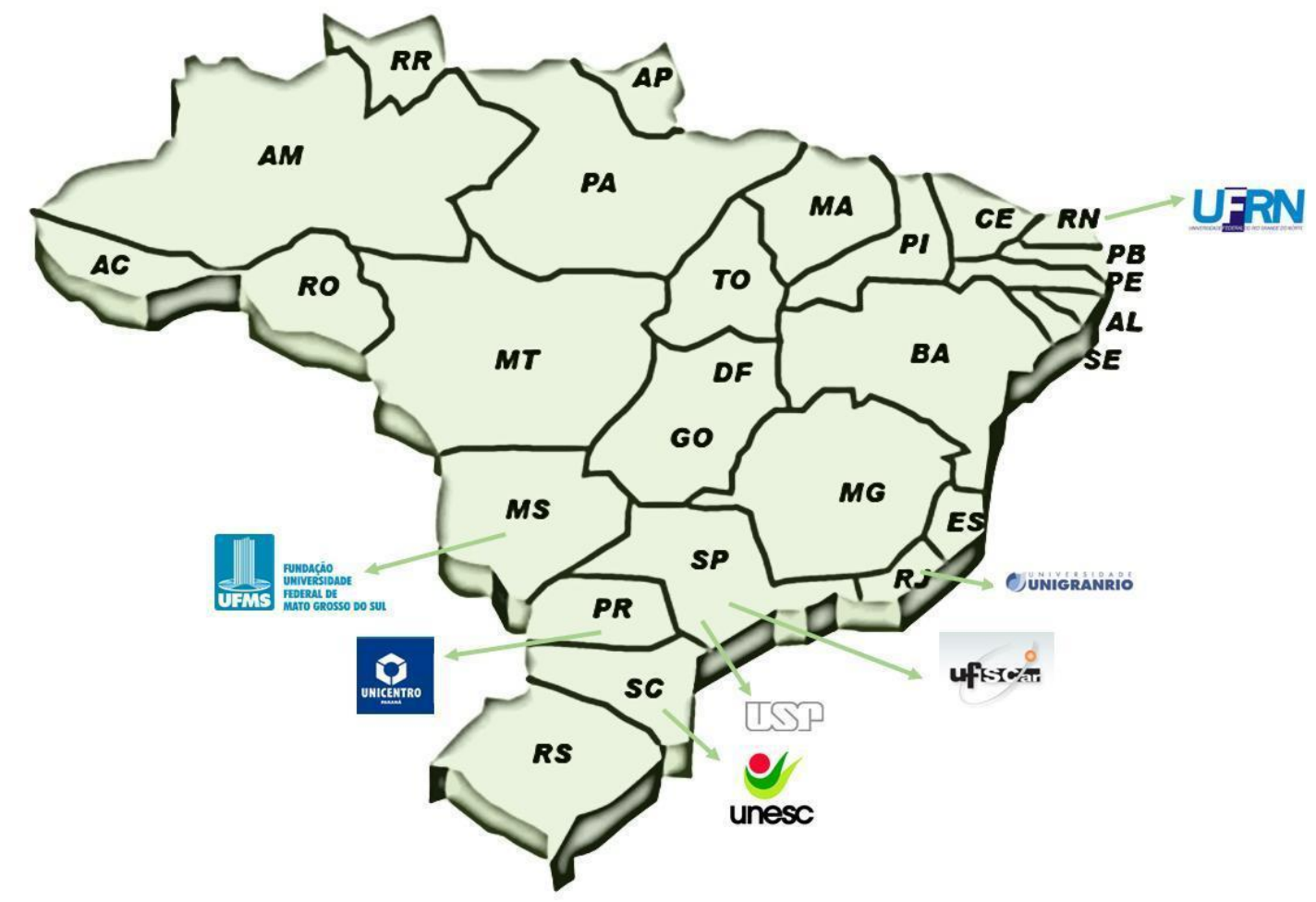

Fonte: https://www.google.com.br/search?q=mapas+do+brasil. Adaptado pela autora (2021).

No mapa com a localização das universidades que possuem pesquisas sobre a relação entre Educação Superior, deficiência e trabalho, pode-se verificar o quanto é urgente debater a questão, uma vez que, seguindo o movimento inclusivo, a Educação Superior se mostra como uma possibilidade de aquisição de competências para a pessoa com deficiência poder incluir-se no mercado de trabalho.

Vale frisar que tais pesquisas foram desenvolvidas nos seguintes programas de PósGraduação: Educação, Educação Especial, Administração e Contabilidade, Desenvolvimento Econômico, Desenvolvimento Comunitário, Humanidades, Culturas e Artes, havendo maior incidência de pesquisas na área da Educação. No quadro 1, apresentam-se os programas e suas linhas de pesquisa. 
http://dx.doi.org/10.5902/1984686X65766

Quadro 1 - Produção Acadêmica nos Programas de Pós-Graduação/Linha de Pesquisa

\begin{tabular}{|c|l|c|}
\hline $\begin{array}{c}\text { Programa de Pós- } \\
\text { Graduação: Área do } \\
\text { Conhecimento }\end{array}$ & Linhas de Pesquisa & No de Trabalhos \\
\hline Educação & Educação & 1 \\
\cline { 2 - 3 } & $\begin{array}{l}\text { Educação e Inclusão nos } \\
\text { Contextos Educacionais }\end{array}$ & 1 \\
\cline { 2 - 3 } & Educação Especial & 1 \\
\hline $\begin{array}{c}\text { Educação Especial } \\
\text { Administração e } \\
\text { Contabilidade }\end{array}$ & $\begin{array}{l}\text { Educação Especial } \\
\text { Controladoria e }\end{array}$ & 1 \\
\hline $\begin{array}{c}\text { Desenvolvimento } \\
\text { Comunitário }\end{array}$ & $\begin{array}{l}\text { Desenvolvimento } \\
\text { Comunitário }\end{array}$ & 1 \\
\hline $\begin{array}{c}\text { Humanidades,Culturas e } \\
\text { Artes }\end{array}$ & $\begin{array}{l}\text { Diversidades Culturais, } \\
\text { espaços e temporalidade }\end{array}$ & 1 \\
\hline $\begin{array}{c}\text { Desenvolvimento } \\
\text { Socioeconômico }\end{array}$ & $\begin{array}{l}\text { Desenvolvimento } \\
\text { Socioeconômico }\end{array}$ & 1 \\
\hline
\end{tabular}

Fonte: Elaborado pela autora a partir da pesquisa (2021).

Observou-se que as pesquisas que relacionam a escolarização da pessoa com deficiência no Ensino Superior ao trabalho, possuem maior campo nos Programas de PósGraduação em Educação, com 3 (três) pesquisas, seguida dos demais programas, com 1(uma) pesquisa. Mediante o número de pesquisas evidenciado, entende-se que há urgência de pesquisas na área da educação sobre a temática, pois em se tratando da pessoa com deficiência, o mercado de trabalho se caracteriza como restrito, exigente e, por isso, excludente, ressaltando-se, assim, que a educação exerce um papel fundamental em sua inserção e permanência.

Após a constatação do número de pesquisas, o quadro 2 exibe-as situando-as em relação à instituição de origem, autor, ano e área do conhecimento. 
http://dx.doi.org/10.5902/1984686X65766

Quadro 2 - Pesquisas que relacionam a escolarização da pessoa com deficiência no Ensino Superior ao trabalho por: instituição, autor, ano e área do conhecimento

\begin{tabular}{|c|c|c|c|}
\hline & $\begin{array}{c}\text { Teses e Dissertações por } \\
\text { Autor }\end{array}$ & $\begin{array}{l}\text { Titulação/ } \\
\text { Instituição }\end{array}$ & $\begin{array}{c}\text { Área do } \\
\text { Conhecimento/Ano }\end{array}$ \\
\hline 1 & $\begin{array}{l}\text { MIRANDA, Bruna da Silva } \\
\text { Ferreira. Da educação } \\
\text { superior para o mundo do } \\
\text { trabalho: perspectivas de } \\
\text { pessoas com deficiência. }\end{array}$ & $\begin{array}{l}\text { Doutorado } \\
\text { UNIGRANRIO }\end{array}$ & $\begin{array}{c}\text { Humanidades, Culturas } \\
\text { e Artes/ } \\
2019\end{array}$ \\
\hline 2 & $\begin{array}{l}\text { CARVALHO, Cristina Linares } \\
\text { de. Pessoas com deficiência } \\
\text { no ensino superior: } \\
\text { percepção dos alunos. }\end{array}$ & $\begin{array}{l}\text { Mestrado } \\
\text { USP }\end{array}$ & $\begin{array}{c}\text { Controladoria e } \\
\text { Contabilidade/2015 }\end{array}$ \\
\hline 3 & $\begin{array}{l}\text { SHIMONO, SumikoOki. } \\
\text { Educação e trabalho: } \\
\text { caminhos da inclusão na } \\
\text { perspectiva da pessoa com } \\
\text { deficiência. }\end{array}$ & $\begin{array}{l}\text { Mestrado } \\
\text { USP }\end{array}$ & Educação/2008 \\
\hline 4 & $\begin{array}{l}\text { PINHEIRO, Maíra Dal'Maz. } \\
\text { Egressos universitários com } \\
\text { deficiência e inserção no } \\
\text { mercado de trabalho } \\
\text { competitivo. }\end{array}$ & $\begin{array}{l}\text { Mestrado } \\
\text { UFRN }\end{array}$ & Educação/2019 \\
\hline 5 & $\begin{array}{l}\text { VITORIO, Janaína Damásio. } \\
\text { Trajetórias de mulheres com } \\
\text { deficiência: do ensino } \\
\text { superior ao mercado de } \\
\text { trabalho sob o olhar do } \\
\text { gênero. }\end{array}$ & $\begin{array}{l}\text { Mestrado } \\
\text { UNESC }\end{array}$ & $\begin{array}{c}\text { Desenvolvimento } \\
\text { Socioeconômico/2017 }\end{array}$ \\
\hline 6 & $\begin{array}{l}\text { FONSECA, Mirella Villa de } \\
\text { Araújo Tucunduva da. Os } \\
\text { discursos sobre a inclusão } \\
\text { social da pessoa com } \\
\text { deficiência: dos desafios } \\
\text { educacionais às conquistas } \\
\text { profissionais. }\end{array}$ & $\begin{array}{l}\text { Doutorado } \\
\text { UFMS }\end{array}$ & Educação/2015 \\
\hline 7 & $\begin{array}{l}\text { CABRAL, Leonardo Santos } \\
\text { Amâncio. Orientação } \\
\text { acadêmica e profissional dos } \\
\text { estudantes universitários } \\
\text { com deficiência: perspectivas } \\
\text { internacionais. }\end{array}$ & $\begin{array}{l}\text { Doutorado } \\
\text { UFSCAR }\end{array}$ & $\begin{array}{c}\text { Educação } \\
\text { Especial/2013 }\end{array}$ \\
\hline 8 & $\begin{array}{l}\text { KUSS, Veridiana Lúcia } \\
\text { Stachowski. Pessoas com } \\
\text { deficiência e o mundo do } \\
\text { trabalho no município de dois } \\
\text { vizinhos/PR. }\end{array}$ & $\begin{array}{c}\text { Mestrado } \\
\text { UNICENTRO }\end{array}$ & $\begin{array}{l}\text { Desenvolvimento } \\
\text { Comunitário/2015 }\end{array}$ \\
\hline
\end{tabular}

Fonte: Elaborado pela autora a partir da pesquisa (2021).

As pesquisas analisadas neste estudo trazem para discussão, questões relacionadas à educação superior, deficiência e trabalho. Acredita-se que a incipiência de estudos que 
http://dx.doi.org/10.5902/1984686X65766

evidenciam tal temática seja em razão da dificuldade em apreciar as subjetividades que compõem a transição da pessoa com deficiência, do ambiente acadêmico para o ambiente organizacional. Os objetivos, sujeitos de pesquisa, instrumentos para a coleta de dados e principais resultados alcançados pelas pesquisas desenvolvidas, serão apresentados na sequência.

\section{Educação superior, deficiência e trabalho: o que revelam as pesquisas}

A Educação Superior se encontra em processo inclusivo. É grande o número de pessoas com deficiência matriculados neste nível de ensino, segundo dados do Instituto de Estudo e Pesquisas Educacionais Anísio Teixeira (INEP), atribuindo-se "ao binômio educação e trabalho" (BRANCO, 2005, p.140) relevância no contexto social. Ressalta-se essa relevância devido ao fato de a educação exercer papel fundamental na inserção e permanência da pessoa com deficiência no mercado de trabalho. Diante desta perspectiva, o que as pesquisas apontam sobre o referido binômio na educação superior?

Tendo como ponto de partida o questionamento acima, traz-se para a discussão as pesquisas desenvolvidas por Shimono (2008), Carvalho (2015), Pinheiro (2019) e Miranda (2019), que discorrem acerca das perspectivas de pessoas com deficiência sobre a educação superior e o trabalho.

Shimono (2008) objetivou desvelar a relação entre a educação e o trabalho de pessoas com deficiência, compreendendo, por meio da história oral, elementos individuais e coletivos que possibilitaram o entendimento do sujeito dentro do contexto histórico e cultural. A autora desenvolveu sua pesquisa tendo como participantes pessoas com deficiência intelectual, visual, auditiva e física. Através da história oral, Shimono (2008) afirma que o acesso à educação torna-se garantia de inserção no mercado de trabalho.

Carvalho (2015), a partir da pesquisa de Shimono (2008), buscou entender a trajetória de vida de alunos com deficiência, graduados, e com alguma passagem pela contabilidade, seja pela graduação, seja pelo ambiente de trabalho. A partir dos pressupostos da metodologia da história oral, utilizou a entrevista aberta como instrumento de pesquisa.

Por meio das narrativas e entrevistas, a autora verificou o crescimento na matrícula de pessoas com deficiência no ensino superior, apontando melhora nas condições das instituições nos últimos anos. Shimono (2009) e Carvalho (2015) destacam como resultados que a inclusão educacional propicia a inserção social, porém há a necessidade de uma formação educacional adequada para o mercado de trabalho. Sinalizam, ainda, que a 
http://dx.doi.org/10.5902/1984686X65766

inclusão de pessoas com deficiência na educação superior não se restringe à matrícula, mas, sobretudo, à qualidade da educação, pois, independentemente das diferenças biológicas, sociais, culturais e ideológicas,todos têm direito à apropriação do conhecimento e à formação para a cidadania.

Quanto à formação na educação superior, ressaltamos a pesquisa de Pinheiro (2019), que teve como objetivo delinear o perfil dos egressos universitários com deficiência, diplomados no período de 2011 a 2017. A pesquisa contou com 32 participantes, os quais responderam o questionário online da plataforma Google Forms. A partir dos resultados, Pinheiro (2019) considerou que a universidade necessita propiciar uma formação que de fato prepare a pessoa com deficiência para inserir-se no mercado de trabalho, considerando as competências e habilidades que a profissão exige e as diversidades inerentes ao ser humano. A autora ainda enfatiza que a universidade precisa pensar estrategicamente na orientação profissional dos acadêmicos com deficiência, preparando-os para a transição (universidade-mercado de trabalho), garantindo práticas profissionais durante a formação acadêmica.

Complementando os resultados apontados nas pesquisas de Shimono (2008), Carvalho (2015) e Pinheiro (2019), destaca-se Miranda (2019), a qual buscou, por meio da história oral, analisar as perspectivas de pessoas com deficiência em fase de conclusão da educação superior, no que diz respeito à inclusão social/profissional no processo de transição do ambiente acadêmico para o ambiente organizacional. Ao analisar as narrativas, Miranda (2019) constatou que a deficiência e as limitações apresentadas não foram determinantes e, muito menos, barreiras impeditivas para alcançar os objetivos pessoais, acadêmicos e profissionais estabelecidos. Cada fragmento de narrativa analisado, cada relato de experiência transcrito e interpretado, evidenciaram a coragem e a determinação dos participantes da pesquisa para vencer as limitações, concluir o nível superior e alcançar a inserção no mundo do trabalho em função compatível com a formação acadêmica adquirida, verificando que o acesso à educação superior torna-se garantia de inserção no mercado de trabalho.

Cabral (2013), em busca por respostas para perguntas que envolvem a orientação acadêmica e profissional de pessoas com deficiência, explorou, em nível internacional, iniciativas relacionadas a esse tema. A pesquisa foi desenvolvida em universidades da Itália, França, Inglaterra, Dinamarca e Irlanda, tendo como participantes pessoas com deficiência. $\mathrm{O}$ autor, com base nos resultados, aponta que foi possível refletir e discutir, em 
uma perspectiva transnacional, a possibilidade de implementar programas eficazes de orientação para pessoas com deficiência, envolvendo os próprios alunos, os atores presentes na universidade (funcionários, professores, colegas de classe, etc) e o território (empresas, instituições, órgãos governamentais, associações, etc). Cabral (2013) relata, ainda, que as reflexões sobre as boas práticas direcionam proposições de indicadores que podem contribuir com a comunidade científica para eventual implementação e acompanhamento de um programa de orientação acadêmica e profissional para estudantes universitários com deficiência.

Kuss (2015) buscou analisar como se dá a relação entre educação e trabalho da pessoa com deficiência no município de Dois Vizinhos/PR. Em sua pesquisa, a autora entrevistou 5 pessoas escolarizadas com deficiência e inseridas no mercado de trabalho (funcionários de 5 empresas e de 2 instituições de ensino). De acordo com Kuss (2015), as entrevistas conferiram que as pessoas escolarizadas com deficiência estão em processo crescente de inserção no meio laboral.

Contudo, a realidade observada é a de que elas desempenham, em sua grande maioria, atividades mecânicas, de pouco desenvolvimento de raciocínio, cumprindo normalmente com sua função de maneira eficiente, eficaz e assídua. Apesar dessa observação, a autora evidencia que as pessoas com deficiência que participaram de sua pesquisa, mencionaram a importância da educação para a obtenção do trabalho formal e para o desenvolvimento pessoal.

Ao encontro de Kuss (2015), Fonseca (2015) buscou compreender como a educação e o trabalho permeiam a inclusão social das pessoas com deficiência. Em sua pesquisa, a autora deu voz aos sujeitos com deficiência e constatou que a titulação acadêmica para a pessoa com deficiência torna-se requisito para inserir-se no mercado de trabalho, mas a instituição educacional, como lócus de formação, não tem cumprido sua função de modo satisfatório.

Ou seja, pouco contribui para que as pessoas com deficiência concorram em nível de igualdade, posto que ainda necessitam de cotas para a tal inserção. A autora destaca que há a necessidade de mudanças nesse cenário, proporcionando à pessoa com deficiência uma formação que de fato a prepare para a inserção no mercado de trabalho de forma igualitária (FONSECA, 2015).

Vitório (2017), para analisar o processo de inserção e permanência das mulheres com deficiência no ensino superior e no mercado de trabalho, entrevistou egressas dos cursos 
http://dx.doi.org/10.5902/1984686X65766

de graduação da Universidade do Extremo Sul Catarinense-UNESC, no período de 2006 a 2014, notando que o acesso ao mercado de trabalho formal para as egressas com deficiência chegou recentemente, sendo que elas ainda precisam lidar com dificuldades diversas ligadas às suas deficiências e associadas à área na qual buscam trabalhar. Alicerçado nos resultados anunciados por Fonseca (2015), Vitório (2017) argumenta que a porta de entrada no mercado de trabalho para muitos profissionais com deficiência ainda é a reserva de vagas garantidas por lei, mas que ainda não há garantias com relação à proporcionalidade do cargo com a competência dos candidatos.

\section{Educação Superior e trabalho: breve discussão}

A educação e o trabalho são direitos fundamentais, garantidos em lei, e se estendem a todas as pessoas, sem distinção, conforme o artigo $6^{\circ}$ da Constituição Federal de 1988 (BRASIL, 1988). A educação é um direito universal e fundamental, garantindo viabilidade para que outros direitos se realizem. Direitos que ampliam as possibilidades de participação ativa no mundo. Porém, faz-se necessário compreender que, para além da necessidade de escolaridade com base nos conhecimentos acadêmicos, a pessoa com deficiência deve ser preparada para a vida social e profissional, pois esta não busca somente certificação, mas um aprendizado que "contribua para a reflexão e a autonomia em diferentes cenários do mundo do trabalho e em todas as esferas do social" (MÉNDEZ, 2013, p. 51).

O anunciado por Méndez (2013) foi apontado nas pesquisas, as quais evidenciaram que a escolarização das pessoas com deficiência na educação superior é um meio importante de acesso ao mercado de trabalho, possibilitando a inclusão social. No entanto, evidencia-se a carência de uma formação que prepare a pessoa com deficiência para inserir-se no mercado de trabalho, considerando as competências e habilidades que a profissão exige.

Assim, surge a necessidade de a universidade pensar estrategicamente na orientação profissional dos acadêmicos com deficiência, preparando-os para a transição (universidade-mercado de trabalho) e garantindo práticas profissionais durante a formação acadêmica. Tal necessidade emerge devido à interdependência que ocorre entre a educação e o mercado de trabalho (FRANZOI, 2006).

Diante dessa interdependência, Brunel (2008) relata que, nas últimas décadas, a relação educação e mercado de trabalho regula e condiciona o ingresso e o retorno dos jovens para a conclusão da escolarização. Ao considerar a centralidade da relação 
http://dx.doi.org/10.5902/1984686X65766

educação e trabalho, torna-se essencial compreender que a sua multidimensionalidade não se vincula apenas aos aspectos econômicos, mas também aos culturais e aos modos de vida. Sob esse viés, é pertinente discorrer brevemente a respeito do trabalho.

O conceito de trabalho, na sua essência, não se resume à questão produtiva. Segundo Raitz (2003), existem diferenças entre emprego e trabalho:

[...] no senso comum e nos próprios meios de comunicação, observa-se que os termos 'emprego e trabalho' são empregados, muitas vezes, de maneira associada, mas essa ligação pressupõe também significados diferentes. Pensando na história da humanidade, o trabalho é mais antigo que o emprego, o trabalho por si só existe desde o momento em que o homem começou a transformar a natureza e o ambiente em seu entorno, desde a fabricação de ferramentas e utensílios. (RAITZ, 2003, p. 56)

A partir do contexto histórico, o trabalho é entendido como uma ação humana sobre a natureza, com o objetivo de transformá-la segundo sua necessidade. Desse modo, o trabalho configura-se em uma relação dialética de mútua transformação permanente entre o ser humano e a natureza (RAITZ, 2009). Com base na autora, o trabalho pode ser visto como componente central na vida do sujeito, visto que permite aprimorar a subjetividade, construir identidade, agir, produzir, pensar e transformar. O emprego, por sua vez, surgiu com a Revolução Industrial, no século XVIII, quando o homem estabeleceu a relação de venda e compra da força de trabalho (RAITZ, 2009). Nesse enlace, o trabalho é concebido como fundamental para o indivíduo, na medida em que impacta a construção do sujeito, o exercício da cidadania, a constituição da subjetividade e a inserção social. Assim, o trabalho torna-se inerente ao ser humano, independente de possuir ou não uma deficiência.

Entretanto, para se compreender o sentido que o trabalho tem para cada sujeito, é imprescindível entender o papel que desempenha na produção da subjetividade. Pensar a subjetividade relacionada ao trabalho, implica pensar os modos como as experiências do trabalho contribuem para formar modos de agir, pensar, sentir e trabalhar (LIMA et al, 2013).

Dessa maneira, pode-se dizer que a transição da universidade para o trabalho é parte integrante de um processo maior, que é a passagem para a vida adulta. A transição para a vida adulta é um processo diverso, visto que "a juventude é uma categoria socialmente construída, formulada no contexto de particulares circunstâncias econômicas, sociais ou políticas; uma categoria sujeita, pois, a modificar-se ao longo do tempo" (PAIS, 2003, p. 37).

Tal transição, segundo Carrano (2004), é vista como uma possibilidade de independência pessoal, uma vez que trabalhar significa sair da esfera doméstica; significa 
relacionar-se socialmente e ter renda própria. Santos (2011), ao descrever sobre os confrontos sociais vivenciados pelas pessoas com deficiência, no que tange à subordinação e ao controle de suas vidas, destaca que a pessoa com deficiência encontra no trabalho o processo de mudança.

Mediante os resultados apresentados nas pesquisas, é possível inferir que as pessoas com deficiência buscam na escolarização o aprendizado e a preparação para os diversos cenários da vida social e do trabalho. Entrelaçados a esse aprendizado, eles estabelecem uma relação entre a escolarização e a possibilidade de inserção no mercado de trabalho, emergindo expectativas. Expectativas essas que envolvem a aquisição da autonomia, da integração social e econômica por meio do trabalho.

\section{Considerações finais}

As pesquisas abordadas neste artigo trouxeram discussões acerca da escolarização da pessoa com deficiência no Ensino Superior e a sua relação com o trabalho. No processo de investigação, tornou-se indispensável considerar as especificidades de cada pesquisa, o olhar do pesquisador perante a realidade estudada, o modo como tratou os dados coletados com vistas a atingir os objetivos propostos e, para além disso, os saberes e perspectivas dos sujeitos envolvidos na pesquisa.

O levantamento realizado nas bases da Coordenação de Aperfeiçoamento de Pessoal de Nível Superior (CAPES) e do Banco Digital de Teses e Dissertações (BDTD) apontou a urgência de debates relativos à questão, pois, seguindo o movimento inclusivo, a Educação Superior se mostra como uma possibilidade de aquisição de competências que permitam à pessoa com deficiência a inclusão no mercado de trabalho. No entanto, vale destacar que essas pessoas não buscam na educação superior somente a certificação para o mercado de trabalho, mas também o aprendizado e a preparação para os diversos cenários da vida social.

As pesquisas encontradas revelam a predominância de relatos sobre a fragilidade da educação superior em ofertar conteúdos acadêmicos efetivamente relacionados ao mercado de trabalho. Evidenciou-se, ainda, que a temática é nova e apresenta literatura escassa, tornando-a, além de relevante nacionalmente, oportuna, também importante para professores, pesquisadores da área, universidades, agentes de políticas públicas e a sociedade como um todo. 
http://dx.doi.org/10.5902/1984686X65766

\section{Referências}

BRANCO, Pedro. Paulo. Martoni. Juventude e trabalho: desafios e perspectivas para as políticas públicas. In: ABRAMO, H.; BRANCO, P. P. M. (org.). Retratos da juventude brasileira: análises de uma pesquisa nacional. São Paulo: Fundação Perseu Abramo, 2005. p.129-148.

BRASIL. Constituição da República Federativa do Brasil. Brasília; Imprensa Oficial, 1988.

BRASIL. Declaração de Salamanca. Sobre Princípios, Políticas e Práticas na Área das Necessidades Educativas Especiais. Disponível em:

http://portal.mec.gov.br/seesp/arquivos/pdf/salamanca.pdf. Acesso: 12 dez 2020.

BRASIL. Lei № 9.394, de 20 de dezembro de 1996. Diário Oficial [da] República Federativa do Brasil, Poder Legislativo, Brasília, DF, 23 dez. 1996. Seção 1, n. 248, p. 27833-27841.

BRASIL. Documento subsidiário à política de inclusão. Ministério da Educação. Secretaria de Educação Especial, Brasília - 2007.

BRASIL. Política Nacional de Educação Especial na Perspectiva da Educação Inclusiva. Documento elaborado pelo Grupo de Trabalho nomeado pela Portaria Ministerial n. 555, de 5 de junho de 2007, prorrogada pela Portaria n. 948, de 09 de outubro de 2008. Brasília, 2008.

BRASIL. Ministério da Educação. A consolidação da inclusão Escolar no Brasil 2003 a 2016. Brasília, DF, 2016.

BRASIL. Lei n. 13.409, de 28 de dezembro de 2016. Altera a Lei n. 12.711, de 29 de agosto de 2012, para dispor sobre a reserva de vagas para pessoas com deficiência nos cursos técnico de nível médio e superior das instituições federais de ensino. Casa Civil, Brasília, 2016. Link de acesso: http://www.planalto.gov.br/ccivil_03/_ato20152018/2016/lei//13409.htm. Acesso: 12 dez 2020.

BRASIL. Decreto n 6.096, de 24 de abril de 2007. Programa de Apoio a Planos de Reestruturação e Expansão das Universidades Federais - REUNI. Casa Civil, Brasília, 2007. Link de acesso: http://www.planalto.gov.br/ccivil_03/_Ato20072010/2007/Decreto/D6096.htm. Acesso: 12 dez 2020.

BRASIL. Decreto n 5.493/2005. Programa Universidade para Todos- PROUNI. Casa Civil, Brasília, 2005. Link de acesso: http://www.planalto.gov.br/ccivil_03/_ato20042006/2005/decreto/d5493.htm. Acesso: 12 dez 2020.

BRASIL. Programa de Acessibilidade na Educação Superior- INCLUIR 04/2008, publicado em Diário Oficial da União n 84, seção 3, páginas 29 e 40 de maio de 2008. http://portal.mec.gov.br/index.php?option=com_docman\&view=download\&alias=132 92-doc-ori-progincl\&category_slug=junho-2013-pdf\&Itemid=30192. Acesso: 12 dez 2020. 
http://dx.doi.org/10.5902/1984686X65766

BRUNEL, Carmem. Jovens cada vez mais jovens na educação de jovens e adultos. 2. ed. Porto Alegre: Mediação, 2008.

CABRAL, Leonardo Santos Amâncio. Orientação acadêmica e profissional dos estudantes universitários com deficiência: perspectivas internacionais. Tese (Doutorado em Educação Especial), UFSCAR, 2013.

CARRANO, Paulo. Educação de jovens e adultos e juventude: o desafio de compreender os sentidos da presença dos jovens na escola da "segunda chance". Revista de Educação de Jovens e Adultos, Belo Horizonte, v.1, n. 0, p. 55-67, ago. 2007. Disponível em: http://www.reveja.com.br. Acesso em: Acesso: 12 dez 2020.

CARVALHO, Cristina Linares de. Pessoas com deficiência no ensino superior: percepção dos alunos. Dissertação (Mestrado em Controladoria eContabilidade) - USP, 2015.

FONSECA, Mirella Villa de Araújo Tucunduva da. Os discursos sobre a inclusão social da pessoa com deficiência: dos desafios educacionais às conquistas profissionais. Tese (Doutorado em Educação), UFMS, 2015

FRANZOI, Naira. Lisboa. Inserção profissional. In: CATTANI, A. D.; HOLZMANN, L. Dicionário de trabalho e de tecnologia. Porto Alegre: UFRGS, 2006. p. 163-165.

FREIRE, Paulo. Pedagogia do Oprimido. 10ª ed. Rio de Janeiro: Paz e Terra, 1981.

GIL, Antônio. Carlos. Como elaborar projetos de pesquisa. 4a edição. São Paulo. Atlas, 2008.

KUSS, Veridiana Lúcia Stachowski. Pessoas com deficiência e o mundo do trabalho no município de Dois Vizinhos/PR. Dissertação (Mestrado em Desenvolvimento Comunitário). UNICENTRO, 2015.

LIMA, Michele. Pinto; TAVARES, Nathália Vasconcelos; BRITO, Mozar José; CAPPELLE,Mônica Carvalho Alves. O sentido do trabalho para as pessoas com deficiência. Rev. Adm. Makenzie. V.14, n.2. São Paulo, mar/abr. 2013.

MÉNDEZ. Natália Pietra. Educação de Jovens e Adultos e o mundo do trabalho in: STECANELA, N. (org.) Cadernos de EJA 1. Caxias do Sul, RS: Educs, 2013

MIRANDA, Bruna da Silva Ferreira. Da educação superior para o mundo do trabalho:perspectivas de pessoas com deficiência. 2019. Tese (Doutorado em Humanidades, Culturas e Artes). UNIGRANRIO, 2019.

PAIS, José. Machado. Culturas juvenis. Porto. Imprensa Nacional da Moeda, 2005.

PINHEIRO, Maíra Dal'Maz. Egressos universitários com deficiência e inserção no mercado de trabalho competitivo. Dissertação (Mestrado em Educação), UFRN, 2019.

RAITZ, Tânia. Regina. Jovens, trabalho e educação: redes de significados dos processos identitários na ilha de Santa Catarina. 2003. 453f. Tese (Doutorado em Educação) - Universidade Federal do Rio Grande do Sul, Porto Alegre, 2003. 
RAITZ, Tânia. Regina; Diversidade de sentidos sobre o trabalho para jovens egressos de cursos de educação profissional. In. XIII Associação Nacional de Psicologia, ABRAPSO, 2009.

SANTOS, Michele. Praita, Alves dos. A formação e a qualificação profissional do jovem com deficiência intelectual e a sua inserção no mercado de trabalho formal de Curitiba. 2011. Dissertação (Mestrado em Educação) - Universidade Federal do Paraná, 2011.

SHIMONO, SumikoOki. Educação e trabalho: caminhos da inclusão na perspectiva da pessoa com deficiência. Dissertação (Mestrado em Educação) - USP, 2008.

UNESCO. Declaração de Salamanca sobre princípios, políticas e prática em educação especial. Espanha, 1994.

UNESCO. Declaração Mundial sobre Educação para Todos: plano de ação para satisfazer as necessidades básicas de aprendizagem. Jomtien, 1990.

UNESCO. Conferência Internacional sobre Educação de Adultos (Declaração de Hamburgo e Agenda para o Futuro). Brasília / Unesco, 1999.

VITÓRIO, Janaína Damásio. Trajetórias de mulheres com deficiência: do ensino superior ao mercado de trabalho sob o olhar do gênero. Dissertação (Mestrado em Desenvolvimento Socioeconômico), UNESC, 2017. 